\title{
Revisiting the Pedicled Gastrocnemius Flap for Orthoplastic Limb Reconstruction
}

\author{
MY Nazri ${ }^{\mathrm{a}}$, AA Akmal \\ ${ }^{a}$ Dept. of Orthopaedic, Traumatology and Rehabilitation.Kulliyyah of Medicine. International Islamic University of Malaysia, Malaysia \\ ${ }^{\mathrm{b}}$ Department of Surgery, Kulliyyah of Medicine. International Islamic University of Malaysia, Malaysia
}

\section{ABSTRACT}

INTRODUCTION: Gastrocnemius muscle flap is performed in a combined approach of the orthopaedic and plastic team for limb reconstruction in the developed countries. However, this practice is not readily available in Malaysia because of the smaller numbers of plastic surgery services in government hospitals. This study reviews the outcome of the gastrocnemius flap performed by the orthopaedic team. MATERIALS AND METHODS: Thirty-two patients underwent gastrocnemius flap surgery with a mean age of 35.3 years (range 13-82). The flaps were done to cover the upper third (22), upper half (4), knee (2), distal femur (2) and the popliteal fossa (1). The initial problems were open fracture (21), infection following plating (5), necrotising fasciitis (3), degloving injury (1), pin site infection (1) and melioidosis (1). Five patients were having underlying Diabetes mellitus, 3 Hepatitis B, 2 HIV and 1 Hepatitis C infections. RESULTS: There was no flap necrosis. Complications include persistence infection in 3 patients which required advancement of the flap (1) and additional fasciocutaneous flap (2) to cover the wound breakdown. All fractures achieved union but one patient with infection following double plating for tibial plateau fracture developed chronic osteomyelitis. One patient develops transient peroneal nerve palsy following the lateral gastrocnemius transfer. Both patients who had patella ligament reconstruction with gastrocnemius flap develop knee stiffness. CONCLUSIONS: Gastrocnemius flap is a reliable and safe procedure in salvaging the leg from amputation related to open fractures and infections in orthopaedic surgery. It should be one of the options for the operative procedure taught during the orthopaedic training.

KEYWORDS: flaps, pedicled, procedure, reconstructive surgical

\section{INTRODUCTION}

Durable soft tissue coverage has been accepted as an integral part of management protocols for limb salvage following open fractures and infections over the last 40 years. ${ }^{1,2}$ The most common and reliable soft tissue

\section{Corresponding Author:}

Prof. Dr. Nazri Mohd Yusof

Department of Orthopaedics, Traumatology and

Rehabilitation,

Kulliyyah of Medicine,

International Islamic University Malaysia,

Jalan Hospital, 25150 Kuantan,

Pahang, Malaysia.

Tel: +6095704000

Email: nazriyusof@iium.edu.my coverage procedure in the lower limb is the gastrocnemius flap because of its superficial location and can be performed without the need for any microscopic instrumentation. The muscle with its vascular pedicle near its origin allows greater rotation of the flap to cover defects from the distal femur to the proximal part of the tibia. 3,4

The muscle's rich blood supply improves drugs delivery, immune response and tissue repair which are important in the management of trauma and infection. The muscles bulk is also used to fill the cavity resulted from surgical debridement. ${ }^{5}$ The main limitation of this flap is its smaller size which limits its use for a small wound. 
However, this limitation has been overcome recently with the use of a combined local flap. This approach has gained acceptance as a valid option for the closure of larger wounds in the leg due to its simplicity and costs effectiveness. ${ }^{6}$

Combined orthopaedic and plastic surgery or the Orthoplastic approach has been advocated in the management of limb reconstruction in the developed countries. ${ }^{7}$ However, this practice is not readily available in Malaysia because of the smaller number of plastic surgery services in government hospitals. Thus, we report our experience in using gastrocnemius muscle flap to cover soft tissues defect and reconstruction of patella ligament resulting from trauma and infection. We hypothesize that local gastrocnemius flap can be safely performed by the orthopaedic surgeon and thus improves the limb salvage of orthopaedic patients that requires soft tissue reconstruction.

\section{MATERIAL AND METHODS}

A consecutive series of 32 patients who underwent gastrocnemius flap surgery in XXXXX Hospital from July 2002 until December 2018 were reviewed retrospectively. Patients who underwent this procedure were those whose wounds were judged to be able to cover by gastrocnemius flap or with a combination of other local flaps such as fasciocutaneous flap or soleus muscle flap. Patients who were excluded were those whose wounds were too large to be covered by a local flap or the muscles were damaged during the trauma. The data of the patients were collected from our medical record maintained in our department.

There were 28 males and 4 females with a mean age of 35.3 years old (range 13-82). Thirty-one flaps were raised from the medial and 5 from the lateral muscle belly. Three patients were combined with fasciocutaneous flap, 2 with soleus flap and 2 cases of the gastrocnemius flap were also included to reconstruct the patella ligament. The flaps were performed to cover the upper third (22), upper half (4), knee (2), distal femur (2) and the popliteal fossa (1). The initial problems were open fracture (21), infection following plating (5), necrotising fasciitis (3), degloving injury (1), pin site infection (1) and melioidosis (1). Five patients have underlying Diabetes mellitus, 3 Hepatitis B, 2 HIV and 1 Hepatitis C infection.

\section{Vascular anatomy}

The gastrocnemius muscles get its' blood supply from the sural artery which is a branch of the popliteal artery at the level of the knee joint. The artery is accompanied by one or 2 large veins that drain into the popliteal vein. The pedicle length varies from $2-5 \mathrm{~cm}$ before it enters the muscle near its proximal origin. After piercing the muscles, the vessels run longitudinally along their entire length just within its deep surface. From the main arteries, secondary arteries arborize throughout the muscle. ${ }^{8}$

Tsetsonis et al. noted that there are communicating vessels between the two heads of the gastrocnemius muscle in their cadaveric study making it possible to raise both heads with only one vascular pedicle. ${ }^{9}$

\section{Operative technique}

The patient is put in a supine position with the hip externally rotated. The surgical procedure was performed under a tourniquet. The muscle was exposed through a midline vertical incision at the posterior of the calf from the popliteal crease to the middle leg. The short saphenous vein and the sural nerve which are in between the two head of gastrocnemius were isolated and preserved. The two muscles head are then separated using scissors or diathermy.

Sharp dissection at its lower musculocutaneous junction separates the muscles from the Achilles tendon. Separating the gastrocnemius and the soleus can be achieved easily with fingers since it is relatively avascular. The muscle belly is then mobilised to cover the defect through a tunnel that is created between the deep fascia and the tibia.

The gastrocnemius origin is detached from the femoral origin when extra length is required to cover the defect. The incision extends proximally and curve to the origin of the muscle for easy access and avoiding flexion contracture of the knee. 
The lateral gastrocnemius flap is performed on the lateral position in which the patient turns to the opposite side of the affected limb. Caution is required when the dissection needs the release of the proximal part of the muscle because of the proximity of the peroneal nerve. Split thickness skin grafting is performed immediately during the same surgery.

\section{RESULTS}

In these procedures, it was observed that there was no flap necrosis among the patients assessed. Complications including persistence infection in three patients which required advancement of the flap (1) and additional fasciocutaneous flap (2) to cover the wound breakdown. All the fractures well united and only one patient who had an infection following double plating for tibial plateau fracture developed chronic osteomyelitis. One of the patients developed transient peroneal nerve palsy following the lateral gastrocnemius transfer. Both patients who had patella ligament reconstruction with gastrocnemius flap develop knee stiffness. One schizophrenic patient eventually underwent above-knee amputation due to infected nonunion of the distal femur.

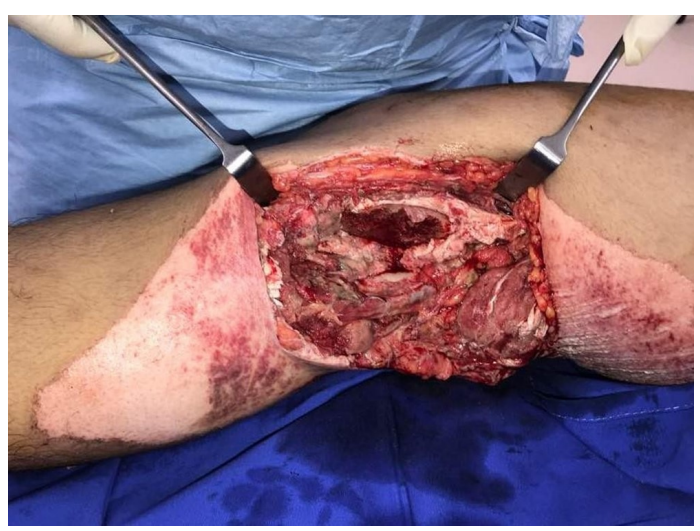

Figure 1A 20-year-old man (case number 28) had a popliteal artery injury following a motor vehicle accident. He had a $10 \times 5 \mathrm{~cm}$ wound at the popliteal fossa. Two $\mathrm{cm}$ of the popliteal artery was resected and replaced with an interposition saphenous vein graft.

\section{DISCUSSION}

Gastrocnemius muscles flap were first popularised by Ger for the treatment of soft tissue defect following open fracture and osteomyelitis. The surgical technique is easy because the plane between the gastrocnemius and soleus muscle are relatively avascular. It does not require any magnification instrument and the vascular

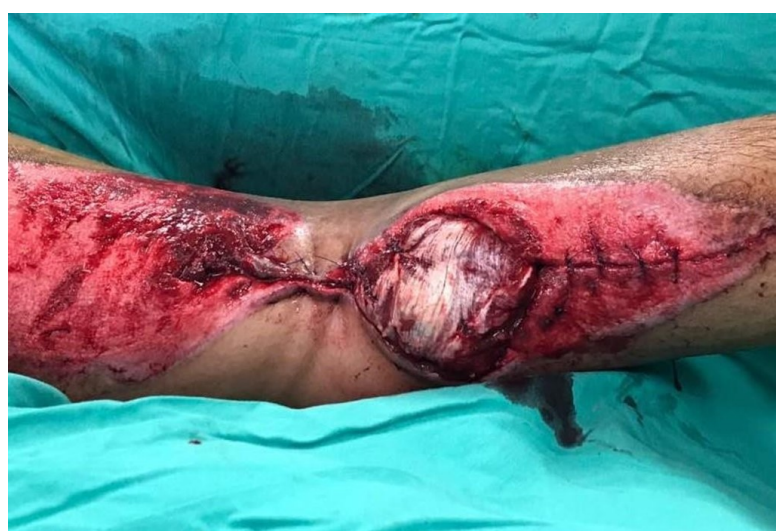

Figure 1B A lateral gastrocnemius flap was raised to cover the anastomosis during the same surgery

pedicle are big and have a persistent location at the knee joint. ${ }^{4}$

Mathes and Nahai classified this flap as a Type 1 muscles flap which has one vascular pedicle supplied the muscle near its origin. ${ }^{10}$ This will allow greater arch of rotation and manipulation of the entire muscle. Arnold and Mixter later improvised the technique to gain more versatility of the flap by detaching the muscles origin and scoring the underlying fascia. ${ }^{11}$ However this procedure can only increase the size of the muscles flap by a few centimetres. We have encountered this problem at the beginning of our series. Now, we commonly use the gastrocnemius myocutaneous flap to cover the large defect in the proximal tibia.

Although easily achieved, complications do occur maybe because of poor planning. The coverage area of the flap is limited by the size of the muscle and the distance that it can reach. The spindle shape of the muscle makes the distal and most important part for coverage even smaller. It is further complicated by disuse atrophy which makes the muscle smaller. We have abandoned the procedure when we found the muscle was injured during the surgery.

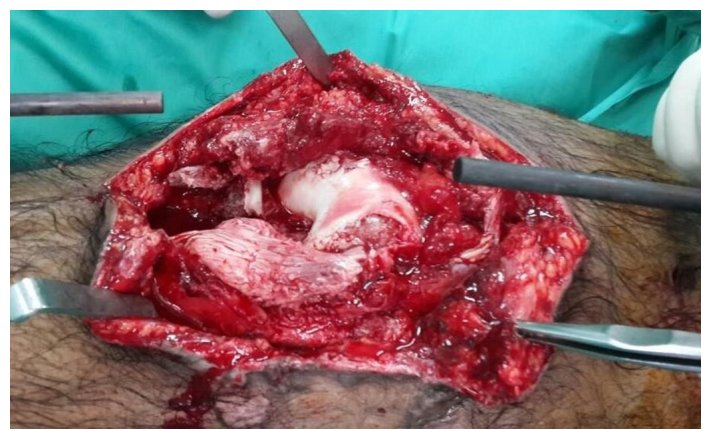

Figure 2A A 24-year-old man (case number 31) was involved in a road traffic accident and sustained grade IIIB open tibial plateau and comminuted patella fractures with a patella ligament tear

IMJM Volume 20 No.2, Apr 2021 
Table I. List of patients undergoing pedicled gastrocmenius flap

\begin{tabular}{|c|c|c|c|c|c|c|c|}
\hline No & Age & Sex & Site & Indication & Operation & $\begin{array}{l}\text { Medical } \\
\text { Problem }\end{array}$ & Outcome \\
\hline 1 & 18 & $\mathrm{~m}$ & upper 3rd tibia & Infection following plating & medial gastrocnemius flap & no & $\begin{array}{l}\text { Healed after transpositional } \\
\text { fasciocutaneous flap }\end{array}$ \\
\hline 2 & 82 & $\mathrm{f}$ & upper 3rd tibia & Open fracture & medial gastrocnemius flap & no & healed \\
\hline 3 & 34 & $\mathrm{~m}$ & upper 3rd tibia & Open fracture & medial gastrocnemius flap & no & healed \\
\hline 4 & 20 & $\mathrm{~m}$ & distal femur & Open fracture & lateral gastrocnemius flap & no & healed \\
\hline 5 & 20 & $\mathrm{~m}$ & $\begin{array}{l}\text { supracondylar } \\
\text { femur }\end{array}$ & Open fracture & medial gastrocnemius flap & no & healed \\
\hline 6 & 31 & $\mathrm{~m}$ & upper 3rd tibia & Open fracture & medial gastrocnemius flap & no & healed \\
\hline 7 & 25 & $\mathrm{~m}$ & upper 3rd tibia & Open fracture & medial gastrocnemius flap & no & healed \\
\hline 8 & 31 & $\mathrm{~m}$ & upper 3rd tibia & Open fracture & $\begin{array}{l}\text { medial gastrocnemius and } \\
\text { soleus muscle flap }\end{array}$ & no & healed \\
\hline 9 & 37 & $\mathrm{~m}$ & upper 3rd tibia & Open fracture & medial gastrocnemius flap & schizophrenia & $\begin{array}{l}\text { Healed, AKA due to non } \\
\text { union of distal femur }\end{array}$ \\
\hline 10 & 23 & $\mathrm{~m}$ & midshaft tibia & Open fracture & $\begin{array}{l}\text { medial gastrocnemius and } \\
\text { fasciocutaneus flap }\end{array}$ & no & healed \\
\hline 11 & 27 & $\mathrm{f}$ & upper 3rd & Infection following plating & medial gastrocnemius flap & IVDU & $\begin{array}{l}\text { died } 1 \text { week post op due to } \\
\text { brain abcess }\end{array}$ \\
\hline 12 & 38 & $\mathrm{~m}$ & midshaft tibia & Open fracture & $\begin{array}{l}\text { medial gastrocnemius, soleus } \\
\text { and fasciocutaneus flap }\end{array}$ & no & healed \\
\hline 13 & 40 & $\mathrm{~m}$ & upper 3rd tibia & Infection following plating & medial gastrocnemius flap & $\begin{array}{l}\text { HIV, Hep } \\
\mathrm{B}+\mathrm{C}\end{array}$ & healed \\
\hline 14 & 37 & $\mathrm{~m}$ & upper 3rd tibia & Open fracture & medial gastrocnemius flap & Hep B & $\begin{array}{l}\text { Healed after advancement } \\
\text { of gastrocnemius flap }\end{array}$ \\
\hline 15 & 20 & $\mathrm{~m}$ & upper 3rd tibia & osteomyelitis at steiman pin site & medial gastrocnemius flap & no & healed \\
\hline 16 & 28 & $\mathrm{~m}$ & upper 3rd & Open fracture & medial gastrocnemius flap & Hep B, HIV & healed \\
\hline 17 & 54 & $\mathrm{~m}$ & upper third & malioidosis osteomyelitis tibia & lateral gastrocnemius flap & NIDDM & healed \\
\hline 18 & 27 & $\mathrm{~m}$ & upper third & Open fracture & medial gastrocnemius flap & no & healed \\
\hline 19 & 54 & $\mathrm{~m}$ & $\begin{array}{l}\text { upper leg and } \\
\text { knee }\end{array}$ & necrotising fasciitis & medial gastrocnemius flap & NIDDM & $\begin{array}{l}\text { Persistence low grade } \\
\text { infection }\end{array}$ \\
\hline 20 & 49 & $\mathrm{~m}$ & upper leg & necrotising fasciitis & medial gastrocnemius flap & NIDDM & healed \\
\hline 21 & 36 & $\mathrm{~m}$ & upper leg & Infection following plating & medial gastrocnemius flap & no & healed \\
\hline 22 & 14 & $\mathrm{~m}$ & midshaft tibia & $\begin{array}{l}\text { degloving injury and open } \\
\text { fracture tibia }\end{array}$ & medial gastrocnemius flap & no & healed \\
\hline 23 & 17 & $\mathrm{~m}$ & upper 3rd & infected open segmental tibia & medial gastrocnemius flap & no & healed \\
\hline 24 & 56 & $\mathrm{~m}$ & $\begin{array}{l}\text { upper half } \\
\text { tibia }\end{array}$ & necrotising fasciitis leg & medial gastrocnemius flap & NIDDM & healed \\
\hline 25 & 43 & $\mathrm{~m}$ & upper 3rd & Infection following plating & lateral gastrocnemius flap & NIDDM & chronic osteomyelitis \\
\hline 26 & 13 & $\mathrm{f}$ & upper 3rd & Open fracture & lateral gastrocnemius flap & no & healed \\
\hline 27 & 25 & $\mathrm{f}$ & upper 3rd & Open fracture & medial gastrocnemius flap & no & healed \\
\hline 28 & 20 & $\mathrm{~m}$ & popliteal fossa & Open fracture & lateral gastrocnemius flap & no & healed \\
\hline 29 & 24 & $\mathrm{~m}$ & knee & Open fracture & $\begin{array}{l}\text { medial gastrocnemius flap and } \\
\text { patella ligament repair, }\end{array}$ & no & $\begin{array}{l}\text { knee stiffness, instability, } \\
\text { delayed wound healing }\end{array}$ \\
\hline 30 & 20 & $\mathrm{~m}$ & upper third & Open fracture & $\begin{array}{l}\text { medial gastrocnemius flap and } \\
\text { refashioning of below knee } \\
\text { amputation stump }\end{array}$ & no & healed \\
\hline 31 & 17 & $\mathrm{~m}$ & knee & Open fracture & $\begin{array}{l}\text { medial gastrocnemius flap and } \\
\text { reconstruction of patella } \\
\text { ligament }\end{array}$ & no & healed, knee stiffness \\
\hline 32 & 30 & $\mathrm{M}$ & Upper third & Open fracture & Medial gastrocnemius flap & No & $\begin{array}{l}\text { Healed after advancement } \\
\text { of fasciocutaneous flap }\end{array}$ \\
\hline
\end{tabular}


We had one patient who had transient peroneal nerve palsy after the lateral gastrocnemius flap. The nerve got kink between the muscle and the neck of the fibula after transposing it to the tibia. Daigeler et al. observed wound problems and peroneal nerve palsy in about 5\% of their patients. ${ }^{12}$

Other than covering the knee and proximal tibia, we also used the lateral gastrocnemius flap to cover the wound at the popliteal fossa and the distal femur. Purkayashta have reported successful coverage of popliteal fossa wound from gunshot injury and Marjolins ulcer. ${ }^{13}$

We did 5 cases where gastrocnemius flap was combined with other local flaps to cover a large defect. We were able to salvage the limb without the need for free soft tissue transfer. $\mathrm{Pu}$ reported his experience of performing 4 cases of combined gastrocnemius and soleus flap to cover a large wound in the midshaft of the tibia. He recommended this procedure when both muscles are not traumatised because it is relatively simpler and more cost-effective than a free tissue transfer. ${ }^{6}$

Our result of repairing the patella ligament with the gastrocnemius tendon is poor because both of our patients develop knee stiffness with a knee range of motion of 0-30 degrees. Extensor tendon reconstruction using gastrocnemius flap has been successfully done in trauma patients. Hohmann et al. reported three of his four patients has returned to work and sporting activity with a median range of motion from 5-95 degrees. ${ }^{14}$

The practice and training of orthopaedic in Malaysia are different from most developed countries. In the United Kingdom, for example, a gastrocnemius flap can only be performed by a plastic surgeon because an orthopaedic surgeon does not have adequate training in this procedure. In the FRCS orthopaedic and trauma speciality curriculum, for example, are only required to know and observed the local muscle and pedicle flap surgery. ${ }^{15}$ However, a different scenario exists in Malaysia where plastic surgery is part of an elective rotation during the Master in Orthopaedic programme. Many orthopaedic trainees assisted plastic surgeon in performing this procedure. They were able to learn this technique quickly because they are familiar with the anatomy of the lower limb.

Malaysia has only 10 plastic surgery service in the ministry of health hospitals as compared to developed countries like the UK where there are 54 plastic departments in the country. ${ }^{16}$ As a result, the wound closure is often delayed and lead to colonisation of bacteria and desiccation of exposing bone and tendon. Many studies have also shown that wound closure within a week of injury has significantly reduced the incidence of infection in open fractures. 17, 18

Pedicle gastrocnemius flap surgery should be thought and perform by orthopaedic surgeons in this country for early soft tissue coverage following debridement of open fracture or osteomyelitis with a small wound around the knee. This idea was also been shared recently by Walton et al., who believes that orthopaedic surgeon should be able to perform a simple rotational gastrocnemius flap after they have understood the anatomy and the application of this procedure. ${ }^{19}$

\section{CONCLUSIONS}

Gastrocnemius flap is a reliable and safe procedure in salvaging the leg from amputation related to open fractures and infections. It should be one of the operative procedures taught during the orthopaedic training.

\section{REFERENCES}

1. Gustilo RB, Mendoza RM, Williams DN. Problems in the management of type III (severe) open fractures: A new classification of type III open fractures. J Trauma. 1984; 24(8): 742-6

2. Lazzarini L, Mader JT, Calhoun JH. Current concept review. Osteomyelitis of long bone. J Bone Joint Surg. 2004; 86A: 2305-18

3. PG Arnold, P Yugueros, AD Hanssen. Muscle flaps in osteomyelitis of lower extremity: a 20 year account. Plast reconstr Surg. 1999; 106: 503-504

4. Ger R. Muscle transposition for treatment and prevention of chronic post traumatic osteomyelitis of the tibia. J Bone Joint Surg. 1977;59A:784-91

5. Mathes SJ, Alpert BS, Chang N. Use of the muscles 
flap in chronic osteomyelitis: experimental and clinical correlation. Plast Reconstr Surg. 1982;69:815-28

6. Pu LL. Soft tissue coverage of an extensive midtibial wound with the combined medial gastrocnemius and medial hemisoleus flaps: The role of local muscle flaps revisited. J Plast Reconstr Aesthet Surg. 2010; 63(8): E605-10. doi: 10.1016/ j.bjps.2010.05.003

7. Nayagam S, K Graham, M Pearse, J Nanchahal. Reconstructive surgery in limbs. The case for the orthoplastic approach. Annals of Plastic Surgery. 2011; 66:6-8

8. Feldman JJ, Cohen BE, May JW. The medial gastrocnemius myocutaneous flap. Plast Reconstr Surg. 1978; 61: 531-9

9. Tsetsonis $\mathrm{CH}$, Koxira OS, Laoulakos DH, Spiliopoulou CA, Koutselinis AS. The arterial communication between the gastrocnemius muscle heads: a fresh cadeveric study and clinical implications. Plast Reconstr Surg. 2000;105:94-8

10. Mathes SJ, Nahai F. Classification of the vascular anatomy of muscles: experimental and clinical correlation. Plast Reconstr Surg. 1981;67:177-87

11. Arnold PG, Mixter RC. Making the most of the gastrocnemius muscles. Plast Reconstr Surg. 1983;72:38-48

12. Daigeler A, Drucke D, Tatar K, Homann H, Goertz O, Tilkorn D, Lehnhardt M, Steinau H. The pedicled gastrocnemius muscle flap: A review of 218 cases. Plast Reconstr Surg. 2009; 123:250-7

13. Purkayastha J. Lateral Gastrocnemius Muscle Flap for Cover of Large Popliteal Fossa Defect following Resection of Marjolin's Ulcer. J Clinical Diagnostic Res.2008; 2(2): 751-3

14. Hohmanna E, Wansbroughb G, Senewiratneb S, Tetsworth K. Medial Gastrocnemius Flap for Reconstruction of the Extensor Mechanism of the Knee Following High-Energy Trauma. A minimum 5 year follow-up. Injury, Int J Care Injured .2016; 47: $1750-5$

15. Specialist training in Trauma and Orthopaedics. Curriculum August 2013. https://www.gmcuk.org/ TO_curriculum_approved_for_August_ 2013.pdf_52146401.pdf

16. Specialty and subspecialty framework of ministry of health under 11th Malaysia Plan (2016-2020).
http://www.moh.gov.my/penerbitan/Pelan\% 20Strategik\%20Bahagian\%20Perkembangan $\%$ 20Perubatan.pdf

17. Godina M. Early microsurgical reconstruction of complex trauma of the extremities. Plast Reconstr Surg. 1986; 78: 285-92

18. Gopal S, Majunder S, Batchelor AG, Knight SL, De Boer P, Smith RM. Fix and flap: The radical orthopaedic and plastic treatment of severe open fractures of the tibia. J Bone Joint Surg Br. 2000; 82: 959-66

19. Walton Z, Armstrong M, Traven S, Lee L. Pedicled rotational medial and lateral gastrocnemius flaps: Surgical technique. J Am Acad Orthop Surg 2017; 25: 744-51 